Article

\title{
Inequalities in the European Union-A Partial Order Analysis of the Main Indicators
}

\author{
Lars Carlsen ${ }^{1, *}$ and Rainer Bruggemann ${ }^{2}$ \\ 1 Awareness Center, Linkøpingvej 35, Trekroner, DK-4000 Roskilde, Denmark \\ 2 Department of Ecohydrology, Leibniz-Institute of Freshwater Ecology and Inland Fisheries, \\ Oskar-Kösters-Str. 11, D-92421 Schwandorf, Germany; brg_home@web.de \\ * Correspondence: LC@AwarenessCenter.dk
}

Citation: Carlsen, L.; Bruggemann, $\mathrm{R}$. Inequalities in the European

Union-A Partial Order Analysis of the Main Indicators. Sustainability 2021, 13, 6278. https://doi.org/ $10.3390 /$ su13116278

Academic Editor:

Abdollah Shafieezadeh

Received: 9 April 2021

Accepted: 29 May 2021

Published: 2 June 2021

Publisher's Note: MDPI stays neutral with regard to jurisdictional claims in published maps and institutional affiliations.

Copyright: (c) 2021 by the authors. Licensee MDPI, Basel, Switzerland. This article is an open access article distributed under the terms and conditions of the Creative Commons Attribution (CC BY) license (https:// creativecommons.org/licenses/by/ $4.0 /)$.

\begin{abstract}
The inequality within the 27 European member states has been studied. Six indicators proclaimed by Eurostat to be the main indicators charactere the countries: (i) the relative median at-risk-of-poverty gap, (ii) the income distribution, (iii) the income share of the bottom $40 \%$ of the population, (iv) the purchasing power adjusted GDP per capita, (v) the adjusted gross disposable income of households per capita and (vi) the asylum applications by state of procedure. The resulting multi-indicator system was analyzed applying partial ordering methodology, i.e., including all indicators simultaneously without any pretreatment. The degree of inequality was studied for the years 2010, 2015 and 2019. The EU member states were partially ordered and ranked. For all three years Luxembourg, The Netherlands, Austria, and Finland are found to be highly ranked, i.e., having rather low inequality. Bulgaria and Romania are, on the other hand, for all three years ranked low, with the highest degree of inequality. Excluding the asylum indicator, the risk-poverty-gap and the adjusted gross disposable income were found as the most important indicators. If, however, the asylum application is included, this indicator turns out as the most important for the mutual ranking of the countries. A set of additional indicators was studied disclosing the educational aspect as of major importance to achieve equality. Special partial ordering tools were applied to study the role of the single indicators, e.g., in relation to elucidate the incomparability of some countries to all other countries within the union.
\end{abstract}

Keywords: Sustainable Development Goals; SDG 10; partial ordering; Hasse diagram; ranking; indicator analyses

\section{Introduction}

On 25 September 2015 the 2030 Agenda and the Sustainable Development Goals (SDG) were adopted [1] comprising the 17 Sustainable Development Goals (SDGs) [2]. In total the 17 SDGs comprise 169 Target and 232 unique indicators [3,4].

Overall sustainability is based on three pillars, i.e., environmentally sound decisions, economically viable decisions, and socially equitable decisions [5]. The present study focusses on SDG 10, Reduced Inequalities that obviously has the primary focus on the social aspect, however, with strong links to the financial aspect. Hence, in relation to SDG 10 the UN explains:

"The intercountryal community has made significant strides towards lifting people out of poverty. The most vulnerable countrys - the least developed countries, the landlocked developing countries and the small island developing statescontinue to make inroads into poverty reduction. However, inequality still persists, and large disparities remain in access to health and education services and other assets" [6].

Recently Eurostat published the 2020 edition of the report "Sustainable development in the European Union. Monitoring report on progress towards the SDGs in an EU context" [7]. 
To elucidate the state of inequalities within the European Union (EU) we have applied partial order methodology using the six main indicators stated by Eurostat (cf. Methodology Section, Table 2) [7]. The analyses have been conducted for the years 2010, 2015 and 2019, respectively including the $27 \mathrm{EU}$ member states, i.e., excluding the United Kingdom. As education and employment are important factors as well in relation to inequalities, additional analyses based on three other indicators: One originates from SDG 4 (Quality education) and two from SDG 8 (Decent work and economic growth) using data from 2019 (cf. Methodology Section, Table 3) [7]. The Eurostat report [7], gives only the actual values as well as the temporal trend for the single indicators (cf. Tables 2 and 3 for specific references) without looking at the combined effect. Here, for the first time an ordering is performed that is based on all SDG10 main indicators simultaneously, without merging them into a single scalar.

\section{Methodology}

\subsection{Why Partial Order?}

When a MIS is to be evaluated methods of multivariate statistics are of primary interest such as, e.g., correlation or regression analyses and clustering techniques. In some studies, just a regression analysis is considered as a method toward an evaluation of a MIS [8]. However, regression analyses need a model concept, e.g., whether a linear model is appropriate or not or whether a nonlinear fitting model appears as a more appropriate choice. To some degree this is also the case for principal component analyses. In the case of cluster analysis, the answer needs a few more remarks. In addition to the technical problem of how to define distances among groups of objects (cf. $[9,10]$ ) cluster analyses have no evaluative background as the clustering is a result of distance measures. Nevertheless, the method appears attractive and attempts to infer posteriori ranking perspectives has been reported (cf. e.g., [11]). Partial order methods have their own disadvantages as, the loss of any metric. However, the evaluative aspect-is its main advantage. The comparison of the objects of interest is done simultaneously for all indicators, without the need of any prior aggregation (details below). In summary, the application of partial order methodology, at least as an interim process before other tools will be applied, is emphasized.

It should be stressed that in the present study the word "inequality" refers to the UN explanation of the term (cf. Introduction). However, it should be noted that inequality also has a deep statistical background and as such they are the origin of much mathematical interest. Usually the term "inequality" is associated with majorization or stochastic order, see [12]. The idea behind majorization theory is the quantification of "spread out". In contrast to majorization theory our aim is not specifically a quantification of the spread out, but the exploration of the role of single indicators in rankings. This trace back to single indicators is to our knowledge not possible in the different tools of majorization theory.

\subsection{Basics of Partial Order Theory}

Several detailed texts about indicator systems and partial order are available (see [13-18]). Hence, here only a brief description is given.

Let us suppose that an "object set" $X$ consists of the objects of interest. $X$ is a finite set. For example, supposing the objects $a, b, c, d$, e we write $X=\{a, b, c, d, e\}$. Furthermore, as the objects are to be compared on the basis of their indicator values, the symbol $\leq$ is used as a binary relation among the objects. The role of this relation is defined by axioms [19]:

Axiom 1: Reflexivity:

$$
x \in X: x \leq x
$$

Axiom 2: Anti-symmetry:

$$
x \leq y, y \leq x \text { implies } x=y
$$


Axiom 3: Transitivity:

$$
x \leq y \text { and } y \leq z \text { implies } x \leq z
$$

Reflexivity means that a given object can be compared with itself. Anti-symmetry means that if both comparisons are valid, i.e., $y$ is better than $x$ and at the same time, $x$ is better than $y$, then this axiom demands that $x$ is identical with $y$. Instead, we accept equivalences (see below (Equation (5))). Transitivity means that if the objects are characterized by properties which are at least ordinal scaled, then any measurable quantity like height, length, price etc. implies transitivity.

\subsection{Product Order}

\subsubsection{Notation}

Let $x, y$ be two different objects of the object set X. Let $Q^{m}$ be the space of measurements (of different scaling levels). If, for instance, data are continuous in concept, then $Q^{m} \subset I R^{m}$ (the $\mathrm{m}$-dimensional space of real numbers). Let $q(x)$ be the data row for $\mathrm{x}$ and $q(y)$ that for y, i.e., $q(x) \in Q^{m}$. We say:

$$
\begin{aligned}
& x \leq y \text { if and only if } q(x) \leq q(y) \\
& q(x) \leq q(y) \text { if and only if } q_{i}(x) \leq q_{i}(y) \text { for all } i
\end{aligned}
$$

The space of measurements, $Q^{m}$, having the order relation property allows to define order relations of the object set on the basis of the set $\left\{q_{1}, \ldots, q_{m}\right\}$, i.e., on the basis of a multi-indicator system (MIS).

If $x, y$ are different objects but $q(x)=q(y)$, i.e., $q_{i}(x)=q_{i}(y)$ for all $i$, then the objects $x$ and $y$ are called equivalent, and the equivalence is denoted as:

$$
x \cong y
$$

The analysis of a MIS by partial ordering is performed by investigation of the representative elements of the equivalence classes generated by (3). Therefore, the symbol $\leq$ is replaced by $<$, i.e., a strict partial order is described by $x<y$.

Consequently $x<y$ if and only if $q(x) \leq q(y)$, i.e., there is at least one indicator with values so Equation (6) is valid.

$$
q(x)<q(y)
$$

The order among the objects based on Equations (4) and (5) is called "product order" or "component-wise order". The notion "component-wise order" makes clear that we will not numerically combine indicator values as is the case in majorization theory. Product order is our method to obtain a partial order from a data matrix.

Often, the condition expressed by Equation (6) cannot be established, and it is very convenient to express this fact by the sign $\|$. The symbol $\|$ expresses that two objects are mutually incomparable due to a conflict among the indicator values of these two objects. If for the objects $x, y$, it is valid that $q(x) \leq q(y)$ or $q(x) \geq q(y)$, then the objects are comparable. In cases where it is not important to know the actual orientation between two objects, in partial order theory this is typically denoted $x \perp y$. When the object set $X$ is equipped with a partial order, the notation $(X, \leq)$ denotes that the objects of $X$ are related to each other by a relation, which obeys the above-mentioned axioms. An object set equipped with a partial order is often called a poset (partially ordered set). Our analysis is based on a data matrix, and from Equation (4) it can be seen that $x \perp y$ or $x \| y$ depends on the attributes used. For a statistical-based analysis it is convenient to introduce the following notion, let A and B be sets, then A $\|$ B if and only if for any object of A, say a, and for every object of $B$, say $b$ it is valid: $a \| b$.

As already mentioned, it is convenient to speak of a multi-indicator-system (MIS) [13], which directs the focus to the fact that several indicators are the basis of an analysis. Thus, $\left(X,\left\{q_{1}, q_{2}, \ldots\right\}\right)$ may, if it is important to refer to the indicators be written as $(X, I B)$. 
Furthermore, the number of objects of a set $\mathrm{A}$ is usually stated as $|\mathrm{A}|$. The set A may be either $X$ or IB or subsets of them.

\subsubsection{Zeta Matrix}

A partial order can be represented by many different ways. Most popular is its representation by a Hasse diagram (see below). Another important representation is to describe the order relations by a square matrix, the "adjacency matrix, $z$ " with the following definition:

$$
z(i, j)=\left\{\begin{array}{c}
1 \text { if } x_{i} \leq x_{j} x_{i}, x_{j} \in X \\
0 \text { otherwise }
\end{array}\right.
$$

This special adjacency matrix describes a directed graph and is called a zeta matrix, $\mathrm{z}$. Whether or not $x_{i} \leq x_{j}$ is determined by Equation (4).

\subsubsection{Concepts of Partial Ordering}

Given a partial order some concepts are of importance:

(1) $\operatorname{Max}(X)$ : the set of objects of $X$, where no other object $y$ can be found with $y>x$. This is the set of maximal objects of a poset. If $x$ is the only maximal object, it is called the "greatest" object.

(2) $\operatorname{Min}(X)$ : the set of objects of $X$, where no other object y can be found with $y<x$. This is the set of minimal objects of a poset. If $x$ is the only minimal object, $\mathrm{x}$ is called the "least" object.

(3) Iso(X): the set of objects of $X$ which are at the same time objects of $\operatorname{Max}(X)$ and $\operatorname{Min}(X)$.

These objects are called isolated objects. Within the context of a MIS the data values leading to objects that are not compared to any other object. These objects are of special statistical interest

(1) Chain: A subset $C$ of $X$, where each object is mutually comparable with others of $C$.

(2) Antichain: A subset AC of $X$, where each object of AC is mutually incomparable with others in AC.

(3) Let $x$ be an object of $C$, then $1(x, C)$ is the length of the chain $C$ including $x$ and is the number of objects in $C$ which are $<=x$. As $x$ may be a member of several chains at once, it is meaningful to define the height $h(x)$ as the $\max \{1(x, C)\}$ taken over all chains, where $\mathrm{x}$ is a member.

(4) Level: The subset of $X$, where all objects have the same height $h(x)$.

The construction of the system of levels taken from a poset is of special importance. Algorithmically, it is not the best way to follow the definition but to define an iterative procedure, as explained in [13]. By levels a weak order for $\mathrm{X}$ is defined. A weak order is an order, where equivalences are accepted.

For example, the sequence $\mathrm{a}<\mathrm{b}=\mathrm{c}<\mathrm{d}<\mathrm{e}=\mathrm{f}$ is not an order, because there are equivalences, but a weak order. From a statistical point of view the fact of equivalences is considered as disadvantageous, because objects are not sufficiently separated. Within the context of partial order, the level structure is often a first attempt to find for $X$ a (weak) order. Note, if $X$ is a chain, i.e., all objects of $X$ are mutually comparable, then each level consists of only one object and then the level structure defines an order.

It is of interest that a simulation with random numbers shows that asymptotically a poset tends to have three levels [20].

\subsubsection{The Hasse Diagram}

A useful visualization of a partially ordered set is the Hasse diagram. A Hasse diagram can be derived from a directed graph, where the vertices are representing the objects and an arrow relates object $x$ with $y$ whenever $x<y$. The steps to obtain the Hasse diagram (note: strict order) from the aforementioned diagrams. Hasse diagrams can be analyzed in a multitude of ways. Two evaluation strategies can be applied: 
(1) Because of transitivity relation the fact $x<y$ and $y<z$ does not need a line for $x<z$, because the lines for $x<y$ and $y<z$ are sufficient.

(2) In a Euclidean plane objects such as $x<y$ is located in that manner that $y$ is located above $x$. By this convention the use of arrows is superfluous.

(3) The drawing by a computer program assumes a grid where all objects are positioned, following rule 2 , so that the representation is as symmetric as possible.

(4) Isolated objects are drawn in that vertical height, where the maximal objects are located too.

Vertical analysis. Here is the focus on finding chains and from them a ranking of objects without the need of further aggregation procedures. Horizontal analysis. Here the focus is on identification of conflicts and which data are causing the main conflicts.

\subsection{Elaborate Analyses}

In the following some tools of partial order theory are presented, which are especially associated with the product order and the needs to support decisions.

\subsubsection{Sensitivity Analysis}

\section{Motivation}

A Hasse diagram has a certain structure (cf. Section 2.3.3). Thus, levels, isolated objects, chains etc. constitute the "structure" of a Hasse diagram and of a partial order. The structure of a Hasse diagram, in turn, is important for an elucidation of the data and their interpretation. The obvious question is, how the single indicators would affect the structure.

\section{Procedure}

The idea is to compare the poset including all indicators with those posets, which arise if one after another indicator is left out. This corresponds to a set of data matrices, where the original data matrix has all the columns corresponding to all indicators $(\mathrm{m})$, and to $\mathrm{m}$ data matrices, where one column is eliminated, i.e., including only $\mathrm{m}-1$ indicators. Consequently, in total $\mathrm{m}+1$ zeta matrices can be calculated by Equation (8), one corresponding to Equation (4) with all indicators, say $\mathrm{z} 0$ and $\mathrm{m}$ zeta matrices with only $\mathrm{m}-1$ indicators in Equation (4), say $z(j), j=1, \ldots, \mathrm{m}$, when the jth indicator is left out By the squared Euclidean distances of $z 0$ vs. $z(j)$ a measure, $D(j)$, is found as to what extent the single indicators, labelled by $\mathrm{j}$ influence the structure of the Hasse diagram:

$$
D(j)=\sum \sum(z 0(i 1, i 2)-z(j)(i 1, i 2))^{2} \quad i 1 i 2=1, \ldots,|X|
$$

Note, the entries of the zeta matrices are 0 or 1 , hence eq. 6 could also be written of a sum of absolute values of the differences (details, see [13]).

$$
D(j)=\sum \sum \mid(z 0(i 1, i 2)-z(j)(i 1, i 2)|\quad i 1 i 2=1, \ldots,| X \mid
$$

\subsubsection{Single Object Analysis}

\section{Motivation}

The application of partial order implies that numerical details are considered as unimportant beside their role to determine whether Equation (7) is fulfilled or not. This a relational point of view (in contrast to a numerical point of view). When an object $x$ is considered in a Hasse diagram it may have neighbors connected by lines downwards and neighbors connected by lines upwards. This is the result of a simultaneous consideration of all indicators, considered within the evaluation of Equation (7). The question is if the relational point of view can be kept and at the same time elucidate what the role of the single indicators for the position of object $x$ is. This analysis is called a "singleobject analysis". 
Procedure

In partial order theory the down- and upsets, generated by object $x$ play an important role. They are defined as follows:

Down set (or "order ideal") generated by $x$ :

$$
O(x):=\{y \in X, \text { with } y \leq x \text { determined by Equation (6) }\}
$$

Up set (or "order filter") generated by $x$ :

$$
F(x):=\{y \in X, \text { with } y \geq x \text { determined by Equation (6) }\}
$$

Equations (10) and (11) can also be evaluated when only one indicator $q(j)$ is considered. If equivalences are excluded, then it is valid:

$$
|O(x)|+|F(x)| \leq|X|+1
$$

When $O(x)(j)$, the down set of $\mathrm{x}$ for the indicator $q_{j}$, and similarly $F(x)(j)$, are determined, then the position of $x$ for indicator $q_{j}$ can be visualized by a mark in a line, where the values $|F(x)(j)|$ and $|O(x)(j)|$ are additional written to the left or right side of the line, see Figure 1.

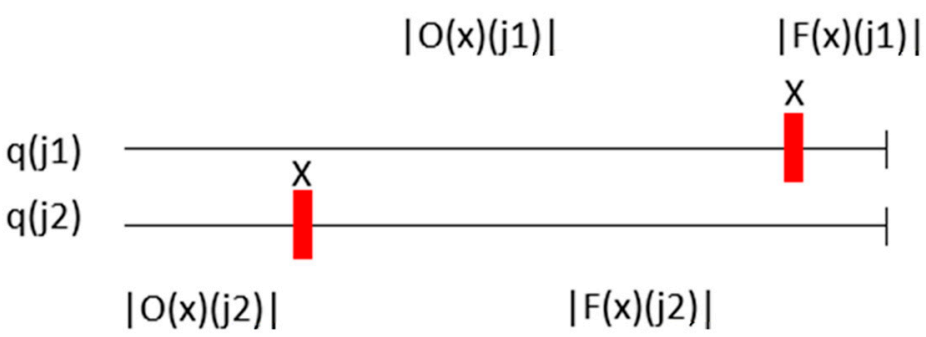

Figure 1. Presentation of object $x$ and the number of objects below and above, respectively, for indicator $q(j 1)$ and for indicator $q(j 2)$.

Figure 1 shows that, considering indicator $q(j 1)$ object $\mathrm{x}$ has many objects below, and pretty few objects above, whereas considering indicator $q(j 2)$ the location of $\mathrm{x}$ is the other way around. The representation by use of indicator-related down- and upsets is attributed to the relational point of view. Crudely, the position of $\mathrm{x}$ allows a numerical view too. Large values, e.g., in $|F(x)(j 1)|$ are only possible when the value $q j 1(x)$ is low and a large value in $|O(x)(j 2)|$ is associated with a high value of indicator $q(j 2)$ for $\mathrm{x}$. The relation between data and the values of down- and upsets for a certain object follows Equations (13) and (14):

$$
\begin{aligned}
& |F(x)(j 1)|>|F(y)(j 1)| \Rightarrow q j 1(x)<q j 1(y) \\
& |O(x)(j 1)|>|O(y)(j 1)| \Rightarrow q j 1(x)>q j 1(y)
\end{aligned}
$$

Remark

The main value of the singleobjects-tool is when different objects are to be compared (see the Results section).

\subsubsection{Isolated Object Analysis}

Motivation

Isolated objects constitute a special subset of the objects investigated, i.e., Xiso $\subseteq X$. It is of interest how objects of Xiso are related with those of Xres:

$$
\text { Xres }:=X-X i s o
$$


Obviously, Xiso can contain every object of interest. Due to the relational point of view, we will characterize the set Xres by statistical measures which do not imply a numerical aggregation procedure, such as arithmetic or geometric mean values.

\section{Procedure}

The objects of Xiso are compared with the $25 \%$-quartile (qu25), the median (qu50) and the $75 \%$-quartile (qu75) together with the minimal and maximal values of Xres. We introduce fictitious objects, whose profiles are the values of min, max, qu25, qu50 and qu75 for each indicator of the real objects of Xres. To illustrate the concept, supposing three indicators, the Xres is characterized by five fictitious objects (Table 1).

Table 1. Profile of the fictitious object based on the Min, qu25, qu50, q75, and Max values from Xres.

\begin{tabular}{|c|c|c|c|}
\hline Fictitious Object & q1 & q2 & q3 \\
\hline "Min" & $\operatorname{Min}\{q 1(y)\}: y \in$ Xres & $\operatorname{Min}\{q 2(y)\}: y \in$ Xres & $\operatorname{Min}\{q 3(y)\}: y \in$ Xres \\
\hline "qu25" & $\begin{array}{c}25 \% \text {-quartile from } \\
q 1(y), y \in \text { Xres }\end{array}$ & $\begin{array}{c}25 \% \text {-quartile from } \\
q 2(y), y \in \text { Xres }\end{array}$ & $\begin{array}{c}\text { 25\%-quartile from } \\
q 3(y), y \in \text { Xres }\end{array}$ \\
\hline “qu50" & $\begin{array}{c}\text { qu50 of } \\
q 1(y), y \in \text { Xres }\end{array}$ & $\begin{array}{c}\text { qu} 50 \text { of } \\
q 2(y), y \in \text { Xres }\end{array}$ & $\begin{array}{c}\text { qu} 50 \text { of } \\
q 3(y), y \in \text { Xres }\end{array}$ \\
\hline "qu75" & $\begin{array}{c}\text { 75\%-quartile from } \\
q 1(y), y \in \text { Xres }\end{array}$ & $\begin{array}{c}75 \% \text {-quartile from } \\
q 2(y), y \in \text { Xres }\end{array}$ & $\begin{array}{c}75 \% \text {-quartile from } \\
q 3(y), y \in \text { Xres }\end{array}$ \\
\hline "Max" & $\operatorname{Max}\{q 1(y)\}: y \in$ Xres & $\operatorname{Max}\{q 2(y)\}: y \in$ Xres & $\operatorname{Max}\{q 3(y)\}: y \in$ Xres \\
\hline
\end{tabular}

The set of fictitious objects as shown in Table 1 is called Xformal. A new poset is constructed, based on

$$
\text { Xstat }:=\text { Xformal } \cup \text { Xiso }
$$

and the indicator values, corresponding to Table 1 with respect to $y \in X r e s$, together with the original indicator values for objects $\in$ Xiso. It is clear by construction that is valid:

$$
\text { Min } \leq q u 25 \leq q u 50 \leq q u 75 \leq \operatorname{Max}
$$

Remark

It cannot be expected that the resulting poset shows a clear picture. It is so-to-say a statistical view where Xiso is compared with Xres. A complete analysis may imply that any single relation of $x \in X i s o$ is to be compared with any single object $y \in$ Xres. Nevertheless, the poset based on Xstat (Equation (16)) is a helpful tool, especially when the poset based on $X$ is large. Subsequent analyses, such as an antichain analysis, performed for Xstat is by far easier when $X$ is large.

\subsubsection{Tripartite Graph}

\section{Motivation}

Which indicator values cause a conflict, i.e., an incomparability, is often awkward, albeit in principle manageable. The concept "Tripartite Graphs" $[21,22]$ supports the user in finding indicator pairs, causing an incomparability by a graphical construction.

\section{Procedure}

$X a c$ is the set of objects of interest. From Xac a set of objects pairs is calculated, where the objects are taken from Xac. For example $X=\{a, b, c, d, e\}, X a c$ may be selected as $\{a, b, c\}$. Then the set of object pairs generated from Xac is $\{(a, b),(a, c),(c, b)\}$. Note, as the incomparability relation is not ordered the sequence of objects within a pair is irrelevant. The tripartite graph consists of three parts: 
(1) vertically oriented list of indicator names in the left side of the diagram

(2) vertically oriented list of object pairs, generated from Xac and

(3) vertically oriented list of indicator names on the very right side.

By this arrangement, the object pairs are in the middle of the graph. Now it is of interest, which indicator causes $x>y$ in $(x, y)$ and which $x<y$ in $(x, y)$. Let $q 1$ be an indicator whose values for $x$ and $y$ lead to $x>y$, then a line is drawn from the list of indicators on the left side; whereas if an indicator $\mathrm{q} 2$ causes $\mathrm{x}<\mathrm{y}$, then a line is drawn from the right side of indicator names to the pair $(x, y)$. Doing this for all pairs a graph is resulting which is called a tripartite graph, because of the parallel arrangement of indicator names, the object pairs and the indicator names. Figure 2 exemplifies the construction under the assumption of three indicators.

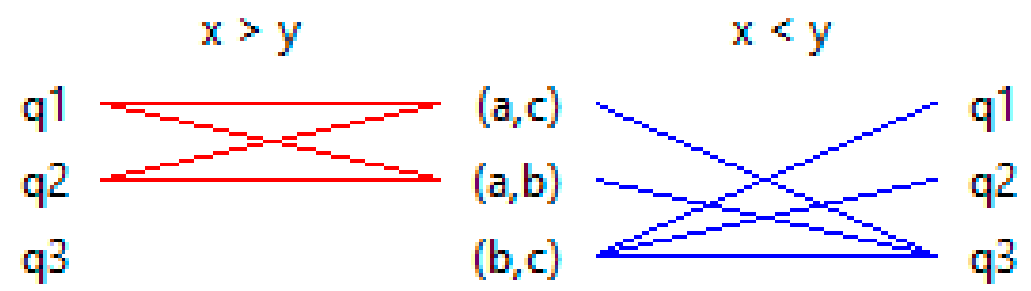

Figure 2. Example of a tripartite graph for $X a c=\{a, b, c\}$ and three indicators. Note: due to technicalities subscripts are not used here.

As Figure 2 shows, the incomparability of a with $\mathrm{c}$ is caused by the indicator pairs (q1, $\mathrm{q} 3)$ and $(\mathrm{q} 2, \mathrm{q} 3)$, whereas that of $(\mathrm{a}, \mathrm{b})$ is caused by $(\mathrm{q} 1, \mathrm{q} 3)$. Objects $(\mathrm{b}, \mathrm{c})$ are comparable.

\section{Remarks}

In general, it is interesting to check which indicator pairs causes the most incomparabilities. In Figure 2 the indicators $\mathrm{q} 1$ and $\mathrm{q} 3$ are striking. Note, here once again we argue completely from the point of view of relational analyses.

\subsubsection{Average Ranks \\ Motivation}

One of the most important tools of partial order is the ability to derive ranks without the need of subjective information related to the indicators in order to aggregate them. In all aggregation processes such as for example the weighted sum of indicator values the primary aim is to derive a scalar, i.e., a one-dimensional quantity, often called a Composite Indicator (CI), which allows to order the objects and thus to rank them. In partial order theory Winkler [23] proposed a method to derive from a partial order a quantity that he called an averaged height for each object of the partially ordered set $X$. The average height in turn implies a weak order (see Section 2.3.3) for the objects of $X$, i.e., ranks.

\section{Procedure}

This method is mainly a combinatorial exercise, and one is confronted with computational difficulties if $X$ is a large set (more than 50 objects). This difficulty triggered many mathematical approaches how to circumvent the computational problems. A pretty famous method is a Monte Carlo Markov chain method proposed by Bubley and Dyer [24]. A 'quick and dirty' method is the concept of local partial order, proposed by Bruggemann et al. [25], where the basic idea is to check the order theoretical environment of each single object $\in X$. The crucial question is, how large must the environment be selected to obtain reliable results. Depending on the selection of the environment different Local Partial Order Models (LPOM) arises. Here the LPOMext is selected, where not only the chains, encompassing object $\mathrm{x}$ are considered but also its incomparable objects $\mathrm{U}(x):=\{y \in X$, with $y \| x\}$ (for details, see [26]). 


\section{Remark}

The LPOM-methods were compared with the results of an exact method, based on lattice theory $[27,28]$ and the results are surprisingly good. Unfortunately, also the exact method by lattice theory fails when $X$ is large.

\subsection{Indicators and Data}

The data was collected from the Eurostat report on the sustainable development in the European Union [7].

\subsubsection{The Indicators}

The Eurostat report focusses on six main indicators as well as 5 additional indicators. In Table 2 the six main indicators are summarized the indicator description being adopted from the appropriate references (see Table 2). It should be emphasized that the orientation of the single indicators is of crucial importance for the analyses in order to make sure that, e.g., high values indicate better. Thus, in cases where lower values indicate better the values will be multiplied by -1 to ensure identical orientation of the data. It should be emphasized that in the case of the Asylum applications by state of procedure, AApp, both the original orientation and the reversed are analyzed as both orientations may be justified based on the general opinion/political decision in the single countries.

Table 2. The six main indicators describing inequalities within the EU.

\begin{tabular}{ccccc}
\hline Indicator & Short & Description (Adopted from the References) & Orientation \\
\hline $\begin{array}{c}\text { Relative median } \\
\text { at-risk-of-poverty gap } 1\end{array}$ & RPG & $\begin{array}{c}\text { The indicator is calculated as the distance between the } \\
\text { median equivalised total net income of persons below the } \\
\text { at-risk-of-poverty threshold and the at-risk-of-poverty } \\
\text { threshold itself, expressed as a percentage of the } \\
\text { at-risk-of-poverty threshold. This threshold is set at } 60 \% \text { of } \\
\text { the countryal median equivalised disposable income of all } \\
\text { people in a country }\end{array}$ & Lower: better \\
& &
\end{tabular}

The indicator is a measure of the inequality of income Income distribution 2 distribution. It is calculated as the ratio of total income received by the $20 \%$ of the population with the highest Lower: better income (the top quintile) to that received by the $20 \%$ of the population with the lowest income (the bottom quintile).

\begin{tabular}{|c|c|c|c|}
\hline $\begin{array}{l}\text { Income share of the } \\
\text { bottom } 40 \% \text { of the } \\
\text { population }{ }^{3}\end{array}$ & Isha & $\begin{array}{l}\text { The indicator measures the income share received by the } \\
\text { bottom } 40 \% \text { of the population. The income concept used is } \\
\text { the total disposable household income. }\end{array}$ & Higher: better \\
\hline $\begin{array}{l}\text { Purchasing power } \\
\text { adjusted GDP per } \\
\text { capita }^{4}\end{array}$ & PPS & $\begin{array}{l}\text { Gross domestic product (GDP) is a measure for the } \\
\text { economic activity ... . Basic figures are expressed in } \\
\text { purchasing power standards (PPS), which represents a } \\
\text { common currency that eliminates the differences in price } \\
\text { levels between countries to allow meaningful volume } \\
\text { comparisons of GDP. }\end{array}$ & Higher: better \\
\hline $\begin{array}{l}\text { Adjusted gross } \\
\text { disposable income of } \\
\text { households per capita }\end{array}$ & AGDI & $\begin{array}{l}\text { The indicator reflects the purchasing power of households } \\
\text { and their ability to invest in goods and services or save for } \\
\text { the future, by accounting for taxes and social contributions } \\
\text { and monetary in-kind social benefits. }\end{array}$ & Higher: better \\
\hline $\begin{array}{l}\text { Asylum applications by } \\
\text { state of procedure }\end{array}$ & AApp & $\begin{array}{l}\text { The indicator shows the number of first-time asylum } \\
\text { applicants per million inhabitants }\end{array}$ & $\begin{array}{l}\text { Not unambiguous (cf. } \\
\text { discussion in text) }\end{array}$ \\
\hline \multicolumn{4}{|c|}{ 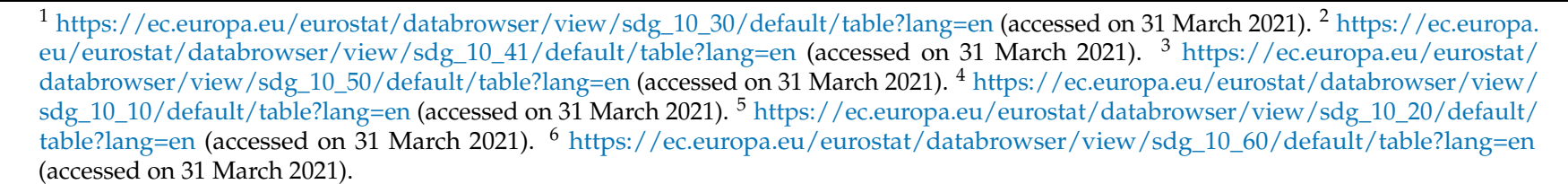 } \\
\hline
\end{tabular}


Out of the five additional indicators [7] the present study includes analyses of the three that focus on education and employment (Table 3). The above remarks concerning orientation obviously also prevail here.

Table 3. The three additional indicators describing inequalities within the EU.

\begin{tabular}{|c|c|c|c|}
\hline Indicator & Short & Description (Adopted from the References) & Orientation \\
\hline $\begin{array}{l}\text { Early leavers from } \\
\text { education and training, } \\
\text { by citizenship }\end{array}$ & EL & $\begin{array}{l}\text { The indicator measures the share of the population aged } 18 \\
\text { to } 24 \text { with at most lower secondary education who were not } \\
\text { involved in any education or training during the four weeks } \\
\text { preceding the survey. }\end{array}$ & Lower: better \\
\hline $\begin{array}{l}\text { Young people neither in } \\
\text { employment nor in } \\
\text { education and training } \\
\text { (NEET), by citizenship }{ }^{2}\end{array}$ & NEET & $\begin{array}{l}\text { The indicator measures the share of the population aged } 15 \\
\text { to } 29 \text { who are not employed and not involved in education } \\
\text { or training. The numerator of the indicator refers to persons } \\
\text { who meet the following two conditions: (a) they are not } \\
\text { employed (i.e., unemployed or inactive according to the } \\
\text { Intercountryal Labour Organisation definition) and (b) they } \\
\text { have not received any education or training (i.e., neither } \\
\text { formal nor non-formal) in the four weeks preceding the } \\
\text { Labour Force Survey (LFS). }\end{array}$ & Lower: better \\
\hline
\end{tabular}

Employment rate, by citizenship ${ }^{3}$
The indicator measures the share of the population aged 20 to 64 which are employed. Employed persons are defined as all persons who, during a reference week, worked at least one hour for pay or profit or were temporarily absent from

\footnotetext{
${ }^{1}$ https:/ / ec.europa.eu/eurostat/databrowser/view/sdg_04_10a/default/table?lang=en (accessed on 31 March 2021). ${ }^{2}$ https: / / ec.europa. $\mathrm{eu} /$ eurostat/databrowser/view/sdg_08_20a/default/table?lang=en (accessed on $31 \mathrm{March} 2021) .{ }^{3} \mathrm{https}: / /$ ec.europa.eu/eurostat/ databrowser/view/sdg_08_30a/default/table?lang=en (accessed on 31 March 2021).
}

\subsubsection{The Data}

The data for the six main indicators for the years 2010, 2015 and 2019 and the three additional indicators for the year 2019 are summarized in Tables 4 and 5, respectively. The tables further give the country codes for the single EU member states. 


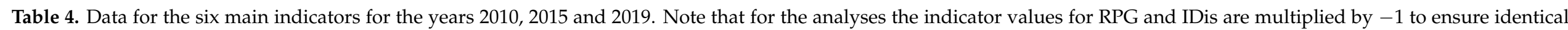
orientation. (for AApp see text).

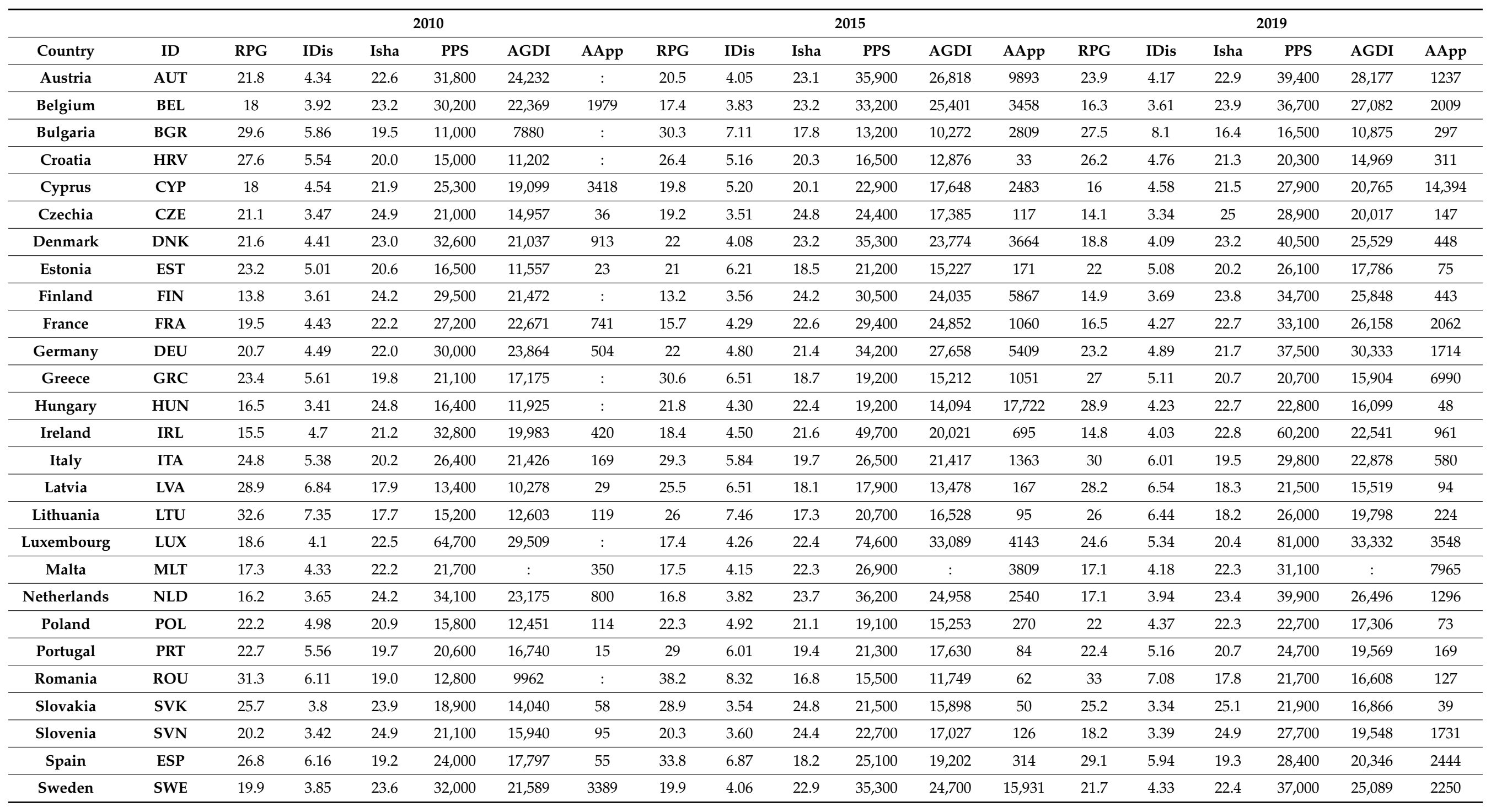


Table 5. Data for the three additional indicators for the year 2019. Note that for the analyses the indicator values for RPG and IDis are multiplied by -1 to ensure identical orientation.

\begin{tabular}{|c|c|c|c|c|}
\hline Country & ID & EL & NEET & ER \\
\hline Austria & AUT & 5.5 & 6.3 & 78.3 \\
\hline Belgium & BEL & 7.3 & 10.6 & 71.8 \\
\hline Bulgaria & BGR & 14 & 16.7 & 75 \\
\hline Croatia & HRV & 3 & 14.2 & 66.8 \\
\hline Cyprus & CYP & 4.9 & 12.7 & 75.8 \\
\hline Czechia & CZE & 6.7 & 9.7 & 80.2 \\
\hline Denmark & DNK & 9.6 & 9.3 & 79.4 \\
\hline Estonia & EST & 9.4 & 9.4 & 81.2 \\
\hline Finland & FIN & 7.1 & 9.3 & 77.9 \\
\hline France & FRA & 7.8 & 12.2 & 72.8 \\
\hline Germany & DEU & 7.6 & 5.7 & 82.7 \\
\hline Greece & GRC & 3 & 16.9 & 61.5 \\
\hline Hungary & HUN & 11.8 & 13.2 & 75.3 \\
\hline Ireland & IRL & 5.2 & 11.2 & 75 \\
\hline Italy & ITA & 11.3 & 21.2 & 63.4 \\
\hline Latvia & LVA & 8.7 & 9.8 & 78.6 \\
\hline Lithuania & LTU & 4 & 11 & 78.2 \\
\hline Luxembourg & LUX & 4.7 & 5.6 & 70.1 \\
\hline Malta & MLT & 15.2 & 6.7 & 76.1 \\
\hline Netherlands & NLD & 7.2 & 5.2 & 81 \\
\hline Poland & POL & 5.3 & 12 & 73 \\
\hline Portugal & PRT & 10.2 & 9 & 76.2 \\
\hline Romania & ROU & 15.4 & 16.8 & 70.9 \\
\hline Slovakia & SVK & 8.4 & 14.5 & 73.4 \\
\hline Slovenia & SVN & 4.1 & 7.6 & 76.6 \\
\hline Spain & ESP & 14.7 & 13.1 & 68.7 \\
\hline Sweden & SWE & 4.8 & 5.5 & 84.5 \\
\hline
\end{tabular}

\subsection{Software}

All partial order analyses were carried out using the PyHasse software [29,30] PyHasse is programmed using the interpreter language Python (version 2.6). Today, the software package contains more than 100 specialized modules and is available upon request from the developer, Dr. R. Bruggemann (brg_home@web.de). A web-based version is under construction [31].

\section{Results and Discussion}

\subsection{Analysis without AApp}

The initial analysis comprise a partial ordering of the $27 \mathrm{EU}$ member states based on the five or six main indicators describing inequalities within the EU applying the common orientation, i.e., the higher the indicator value the better (cf. Table 2). In Figure 3 the Hasse diagrams for the years 2010, 2015 and 2019 are shown applying the five indicators RPG, IDis, Isha, PPS, AGDI. It should noted that in all three cases Malta (MLT) has been excluded from the analyses due to missing data. 


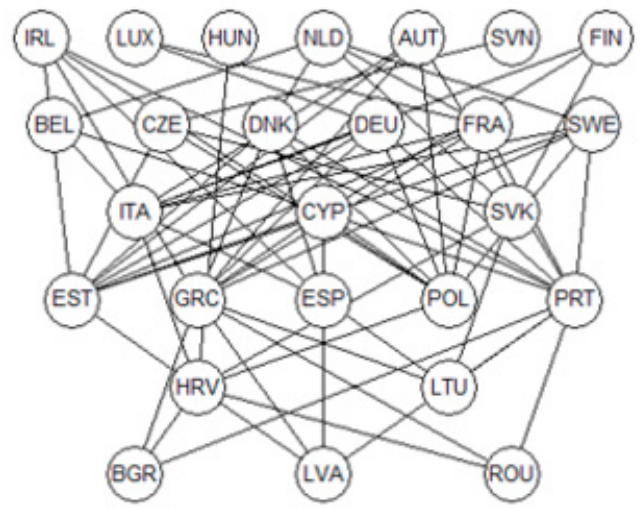

2010

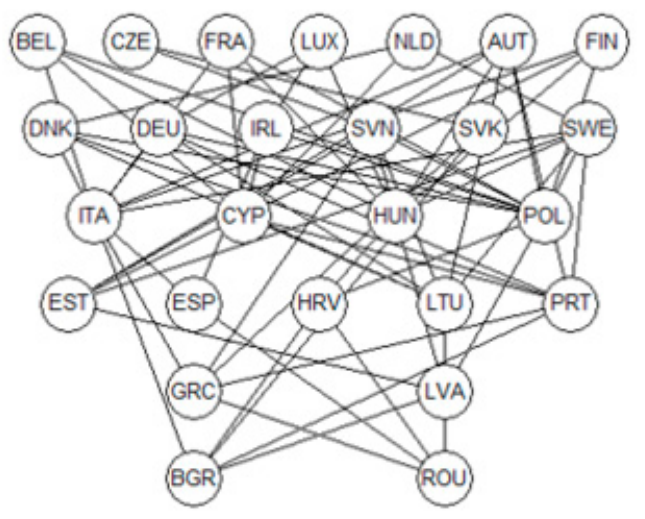

2015

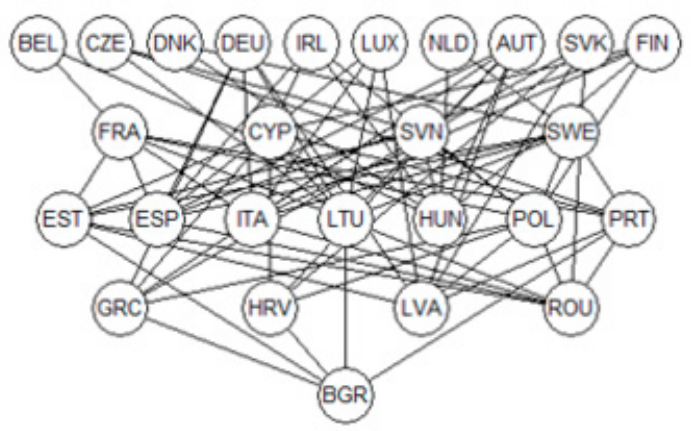

2019

Figure 3. Hasse diagram applying the indicators RPG, IDis, Isha, PPS, AGDI (cf. Table 1) for 2010,2015 and 2019. The number of comparabilities and incomparabilities for the 3 diagrams are 182/143, 179/146 and 157/168, respectively.

It can immediately be noted that the three diagrams displaying the development in the degree of equalities over the years are different. However, it can also be noted that some countries like, e.g., AUT, FIN, LUX and NLD for all three years are found at the top level, whereas countries like BGR are found in the bottom of the diagrams, reflecting the highest and lowest degree of equalities within the EU, respectively. The year 2019 comprises a Hasse diagram with only five levels, whereas for the other two years six levels were found. The year 2019 bears obviously remarkably more conflicts than the other two years.

A more elaborate view on the mutual ranking of the 26 member states is obtained by calculating the average rank, where 1 is the top/best and 26 the bottom/worst, respectively. In Table 6 the calculated average ranks for the 26 Member states included in the analysis are displayed for the three years.

It is from Table 6 immediately possible to see the development-positive or negativein the degree of equality for the single countries. Striking examples are BEL and DNK where an increase from rank 6 to rank 5 to rank 1 and from 10 and 10.5 in 2010 and 2015, respectively to rank 2.5 in 2019, respectively are seen. On the other hand, e.g., LUX and SWE decrease from rank 2 in 2010 and 2015 to rank 9 in 2019 and from 8 in 2010 and 2015 to rank 11 in 2019, respectively, are noted. 
Table 6. Comparison of the average rank of the 26 EU member states. based on the 5 main indicators. Note Malta has been excluded due to missing data.

\begin{tabular}{|c|c|c|c|}
\hline & 2010 & 2015 & 2019 \\
\hline & rank & rank & rank \\
\hline AUT & 5 & 7 & 7 \\
\hline BEL & 6 & 5 & 1 \\
\hline BGR & 24.5 & 25 & 26 \\
\hline CYP & 14 & 13 & 14 \\
\hline CZE & 11 & 3 & 6 \\
\hline DEU & 9 & 10.5 & 8 \\
\hline DNK & 10 & 10.5 & 2.5 \\
\hline ESP & 21 & 20 & 20 \\
\hline EST & 19.5 & 19 & 17 \\
\hline FIN & 3 & 5 & 4 \\
\hline FRA & 12 & 5 & 10 \\
\hline GRC & 17.5 & 24 & 23 \\
\hline HRV & 22 & 22 & 22 \\
\hline HUN & 13 & 16 & 21 \\
\hline IRL & 7 & 9 & 5 \\
\hline ITA & 15 & 15 & 18 \\
\hline LTU & 23 & 21 & 19 \\
\hline LUX & 2 & 2 & 9 \\
\hline LVA & 26 & 23 & 24 \\
\hline NLD & 1 & 1 & 2.5 \\
\hline POL & 19.5 & 17 & 15 \\
\hline PRT & 17.5 & 18 & 16 \\
\hline ROU & 24.5 & 26 & 25 \\
\hline SVK & 16 & 14 & 13 \\
\hline SVN & 4 & 12 & 12 \\
\hline SWE & 8 & 8 & 11 \\
\hline
\end{tabular}

These changes in the ranking for the mentioned four countries are obviously reflections of changes in the indicator values (cf. Table 4). Thus, in the case of BEL and DNK pronounced increases in the PPS and AGDI values are seen, the orientation of both indicators is the higher the better. On the other hand, for LUX and SWE markable increases in the RPG and IDis values are noted, both indicators having a lower the better orientation.

In this connection it is interesting to have a look at the relative importance of the five indicators. For all 3 years it appears that the RPG and the AGDI indicators are the those with the highest influence on the partial ordering. Hence, for the 3 years the RPG, AGDI were estimated to be 2010: 0.36, 0.41, 2015: 0.49, 0.29 and 2019: 0.47, 0.26, respectively. Apparently, the influence of the relative median at-risk-of-poverty gap is increasing over the years whereas the influence of the adjusted gross disposable income of households per capita is decreasing.

It should be emphasized that what is seen in Table 5 is the mutual ranking of the 26 member states. Thus, the calculated average ranks cannot be taken as an absolute measure of the degree of equality in the single countries. 


\subsection{Analysis Including AApp}

Turning to an analysis where the number of first-time asylum applicants are included, a completely different picture develops. Due to missing data for nine member states on the asylum applicants for the year 2010, only the year 2015 and 2019 have been studied. Inclusion of the indicator AApp can be done in two ways, i.e., with two scenarios characterized by an orientation where A: 'the lower the better' or where B: 'higher the better', respectively, prevails. This is obviously a political discussion/decision in the single member states what is preferred. In the present study both scenarios have been analyzed. However, independently of the indicator orientation it is found that the AApp indicator display an overwhelming influence on the partial ordering. A less significant influence was observed for the RPG indicator. Thus, the relative AApp influence for 2015 and 2019 for the two scenarios were found to be 2015 A: 0.86 , B: 0.57 and 2019 A: 0.77, B: 0.65 . The corresponding influence for the RPG indicator was 2015 A: 0.07, B: 0.22 and 2019 A: 0.10, B: 0.17. In Figure 4 the Hasse diagrams for the two scenarios for 2019 are shown.

\section{A}

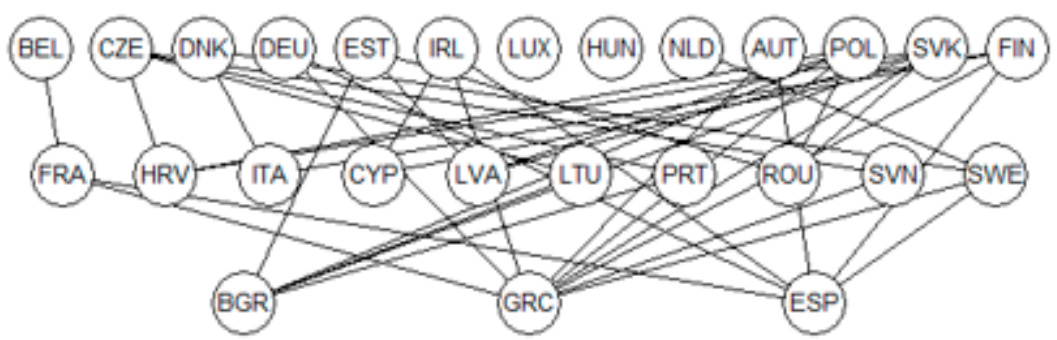

B

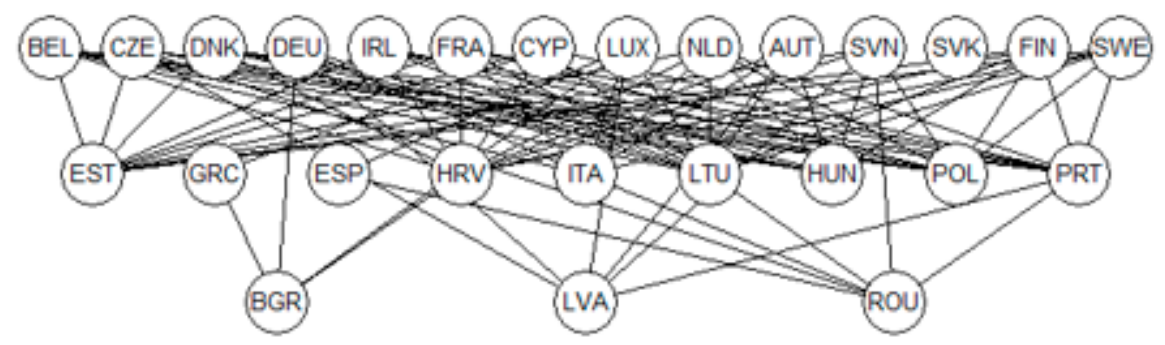

Figure 4. Hasse diagram applying the indicators RPG, IDis, Isha, PPS, AGDI, AApp (cf. Table 1) for 2019 for (A): 'the lower the better' and (B): 'the higher the better' orientation for the AApp indicator. The number of comparabilities and incomparabilities for the 2 diagrams are $47 / 278$ and $110 / 215$, respectively.

Most striking is that now the Hasse diagrams have only three and four levels. Furthermore, Figure 4 shows some variations, but also some more pronounced changes in the locations for some member states as function of AApp orientation. First it is noted that LUX and HUN are isolated objects.

Further it is noted that ESP GRC that are found at the bottom of the diagram for scenario A are found at the middle level for scenario B. The opposite can be seen for LVA. In scenario A CYP is found at the middle level and at the top in scenario B. Here it should be remembered that objects in the Hasse diagram is by convention located as high as possible. However, CYP is a minimal object (cf. Section 2.3.3). A clearer variation in the mutual ranking as a function of scenario and year is shown in Table 6 where the average rankings are summarized. Here it is noted that CYP moved from a rank 20 in the A-scenario to a rank of 14 in 2015 and 3 in 2019 in the B-scenario (Table 7), in accordance with the number of migrants to CYP in 2015: 2483 and in 2019: 14394 (cf. Table 3). From Table 7 the effect of HUN virtually closing the border for migrants can be seen, the AApp values being 17,722 and 48 for 2015 and 2019, respectively (Table 4). 
Table 7. Comparison of the average rank of the EU member states based on all 6 main indicators for the year 2015 and 2019. For indicator AApp the orientation A: lower = better and B: higher = better was adopted was adopted. Note year 2010 has been excluded due to missing data and for 2015 and 2019 Malta has been excluded due to missing data.

\begin{tabular}{|c|c|c|c|c|c|}
\hline A & 2015 & 2019 & B & 2015 & 2019 \\
\hline & rank & rank & & rank & rank \\
\hline AUT & 11 & 10.5 & AUT & 5.5 & 10 \\
\hline BEL & 11 & 7 & BEL & 2.5 & 1.5 \\
\hline BGR & 26 & 24 & BGR & 20 & 25 \\
\hline CYP & 20 & 20 & CYP & 14 & 3 \\
\hline CZE & 1 & 1 & CZE & 10 & 12 \\
\hline DEU & 22 & 10.5 & DEU & 7.5 & 13 \\
\hline DNK & 21 & 4 & DNK & 7.5 & 7 \\
\hline ESP & 13.5 & 25 & ESP & 21 & 16 \\
\hline EST & 18 & 6 & EST & 18 & 23 \\
\hline FIN & 11 & 5 & FIN & 2.5 & 7 \\
\hline FRA & 3 & 12 & FRA & 9 & 4.5 \\
\hline GRC & 24 & 26 & GRC & 22 & 15 \\
\hline HRV & 8 & 21 & HRV & 25 & 19 \\
\hline HUN & 25 & 14.5 & HUN & 11 & 21 \\
\hline IRL & 4 & 9 & IRL & 12 & 7 \\
\hline ITA & 16 & 19 & ITA & 15 & 18 \\
\hline LTU & 13.5 & 14.5 & LTU & 23 & 20 \\
\hline LUX & 7 & 14.5 & LUX & 1 & 8 \\
\hline LVA & 18 & 22.5 & LVA & 24 & 24 \\
\hline NLD & 2 & 8 & NLD & 4 & 1.5 \\
\hline POL & 18 & 2.5 & POL & 17 & 22 \\
\hline PRT & 9 & 14.5 & PRT & 19 & 17 \\
\hline ROU & 23 & 22.5 & ROU & 26 & 26 \\
\hline SVK & 5 & 2.5 & SVK & 16 & 14 \\
\hline SVN & 6 & 17 & SVN & 13 & 11 \\
\hline SWE & 15 & 18 & SWE & 5.5 & 4.5 \\
\hline
\end{tabular}

To elucidate the isolated location of the two countries LUX and HUN (Figure 4A), two questions need answers:

(1) Why are LUX and HUN mutually incomparable? and

(2) Why are HUN and LUX not connected, i.e., incomparable to all other countries.

To answer the first question a 'singleobjectanalysis' of LUX and HUN, respectively (Figure 5), leads to the answer. 
A

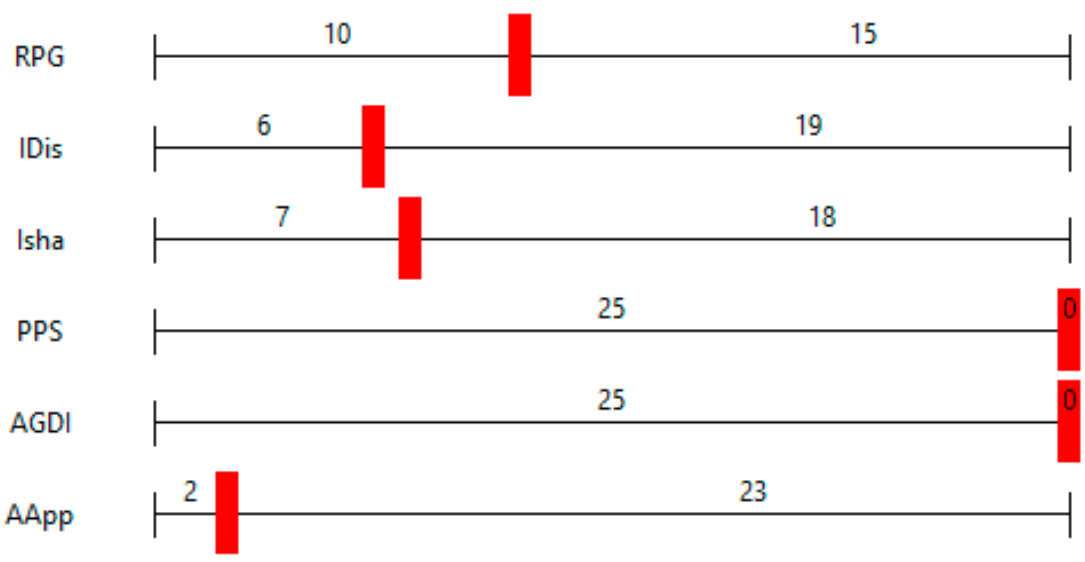

B

RPG

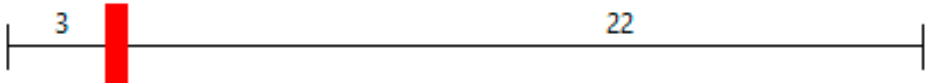

IDis

Isha

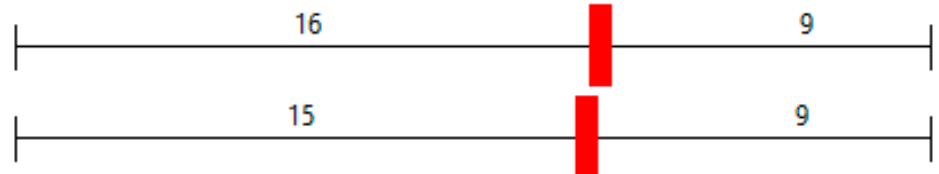

PPS

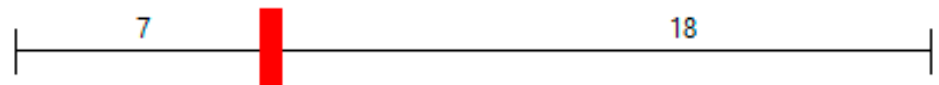

AGDI

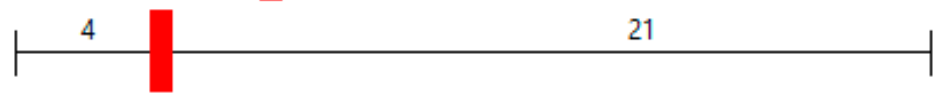

AApp

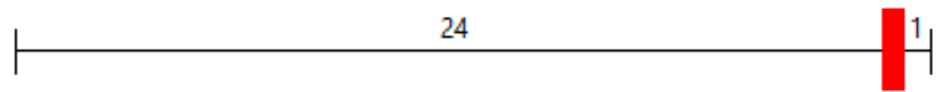

Figure 5. Results of "singleobjectsanalysis" of (A): LUX and (B): HUN.

It is immediately seen (cf. also Table 4) that with respect to indicators PPS and AGDI the country LUX is a maximal object, even (pretty trivial, as only one indicator is considered at time) a greatest object. Thus, following equations (13) and (14) LUX has top values and low values with respect to indicators PPS and AGDI and AApp, respectively. In contrast to this, HUN has pretty low values with respect to indicators PPS and AGDI but almost top position with respect to indicator AApp. Hence, the incomparability HUN \| LUX is obviously caused by the indicators PPS, AGDI and AApp. Other indicators may also lead to incomparability; however, the incomparabilities caused by these three indicators is most striking.

To elucidate the relation of HUN and LUX, respectively to the other objects (i.e., to answer the second question: why HUN $\| X-\{H U N, L U X\}$ and why LUX $\| X-\{H U N, L U X\}$ (notation: see Secion 2.3.1)? These calculations were based on the "isolatedobject" tool in combination with a subsequent antichain analysis. In other words, what arguments lead to Xiso $\|$ Xres. This is done by statistically characterization of the set Xres comprising the fictitious objects min, qu25, qu30, qu75 and max. See Table 8. 
Table 8. Indicator values for the fictitious object from Xstat (cf. Figure 4A and Section 2.4.3).

\begin{tabular}{ccccccc}
\hline & RPG & IDis & Isha & PPS & AGDI & AApp \\
\hline min & -33.0 & -8.1 & 16.4 & $16,500.0$ & $10,875.0$ & $-14,394.0$ \\
\hline qu25 & -27.0 & -5.9 & 19.5 & $21,900.0$ & $16,866.0$ & -2009.0 \\
\hline qu50 & -22.2 & -4.5 & 22.0 & $28,150.0$ & $20,181.5$ & -514.0 \\
\hline qu75 & -16.5 & -3.9 & 23.4 & $37,000.0$ & $25,848.0$ & -147.0 \\
\hline max & -14.1 & -3.3 & 25.1 & $60,200.0$ & $30,333.0$ & -39.0 \\
\hline \multicolumn{2}{c}{ Isolated objects } & & & & & \\
\hline LUX & -24.6 & -5.34 & 20.4 & $81,000.0$ & $33,332.0$ & -3548.0 \\
\hline HUN & -28.9 & -4.23 & 22.7 & $22,800.0$ & $16,099.0$ & -48.0 \\
\hline
\end{tabular}

The set Xstat (cf. Equation (16)) can be partially ordered and its Hasse diagram is shown in Figure 6.

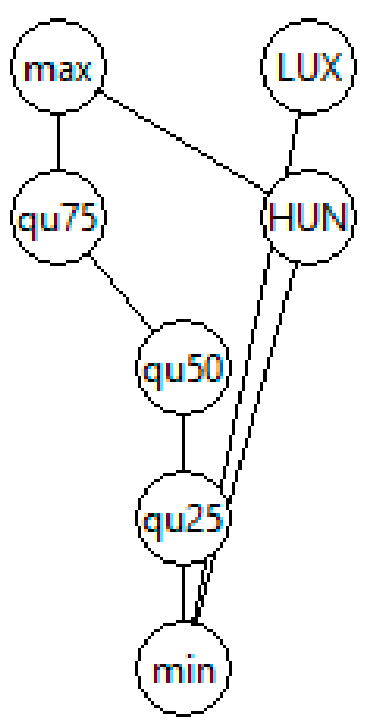

Figure 6. The Hasse diagram of the set Xstat (Equation (16)).

Following Equation (17) the fictitious objects min, qu25, qu50, qu75 and max obviously form a chain. Thus, the main interest is, how LUX and HUN are order theoretically positioned relative to this chain. Here it is immediately noted that neither LUX nor HUN are comparable with max, which means that that both LUX and HUN must have at least one indicator with a larger value than max and at least one indicator with lower values of max. The tripartite tool (cf. Section 2.4.4) graphically discloses how HUN and LUX is related to the qu25, qu50 and qu75 objects in the fictitious object (Figure 7). 


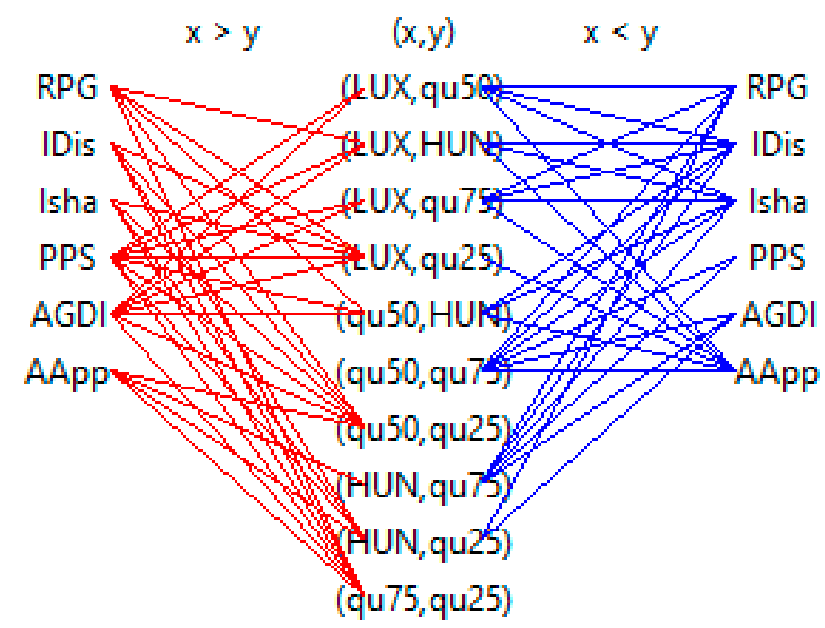

Figure 7. Tripartite graph for Xac: $=\{H U N$, LUX, qu75, qu50, qu25 $\}$.

From Figure 7 it is immediately clear in the case of LUX the AApp indicator is higher for qu25 than for LUX whereas the reverse is true for the remaining 5 indicators, thus LUX || qu25. Similar conflicts are noted for the LUX, qu50, LUX, qu75 and LUX, HUN relations. Consequently, it can be concluded based on the "isolatedobject tool" that LUX and HUN are incomparable to most objects of Xres and HUN.

\subsection{Additional Indicators}

As mentioned in the introduction Eurostat in addition to the six main indicators (Table 2) also points at some additional indicators that originally are indicators for SDG 4 (EL) and from SDG 8 (NEET and ER) (Table 3). The partial ordering of the 27 EU member states according to these three indicators is visualized by the Hasse diagram in Figure 8 that comprises 147 comparisons and 204 incomparisons, respectively.

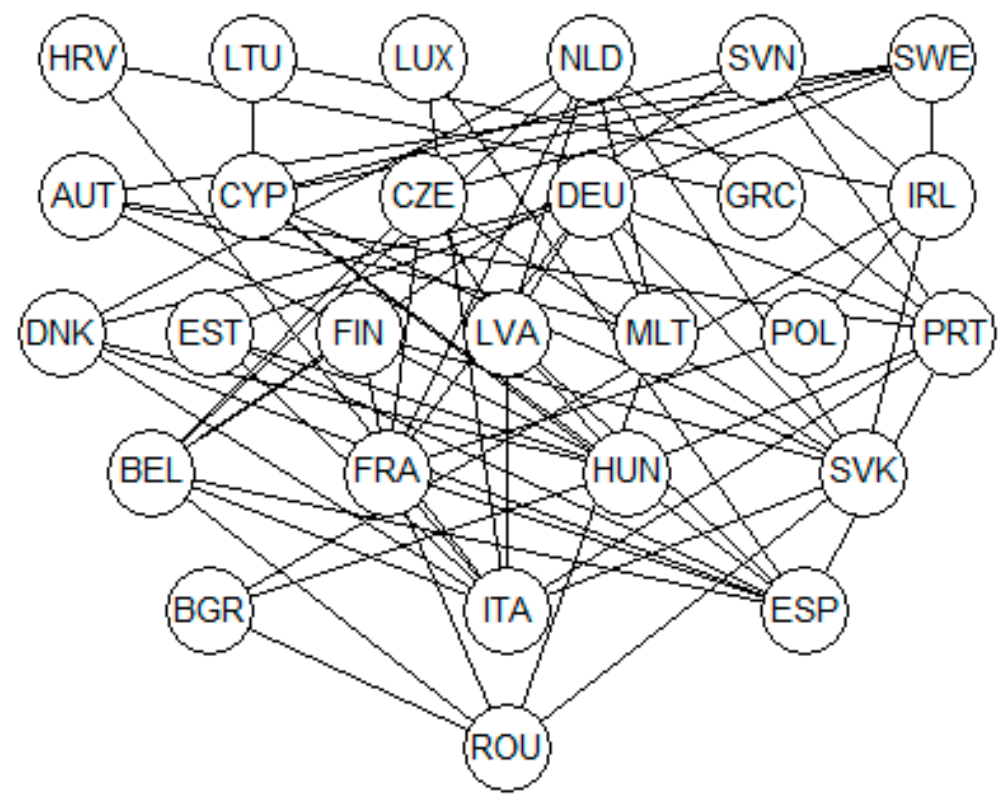

Figure 8. Hasse diagram visualizing the partial ordering of the $27 \mathrm{EU}$ member states based on the indicators EL, NEET and ER (cf. Tables 2 and 4).

A sensitivity analysis unambiguously discloses that the EL, i.e., the educational aspect (cf. Table 3), not surprisingly (cf. [32]) by far is the most important indicator for the ordering. 
The top five members states are SWE $>$ SVN $>$ NLD $>$ LTU $>$ DEU, whereas the five lowest ranked states were found to be $\mathrm{HUN}>\mathrm{BGR}>\mathrm{ESP}>\mathrm{ITA}>\mathrm{ROU}$, respectively.

\section{Conclusions and Outlook}

The sustainable development goal 10 (SDG 10) deals with the inequality in the different countries. The inequality has, by Eurostat, been characterized by six main indicators. In the present study the degree of inequality in the 27 European Union member states been analyzed applying the partial ordering framework. Thus, all indicators have been included simultaneously and without any pretreatment. The degree of inequality was studied for the year 2010, 2015 and 2019.

Two sets of analyses were conduction. The first set applied only five indicators, i.e., RPG: Relative median at-risk-of-poverty gap, IDis: Income distribution, Isha: Income share of the bottom $40 \%$ of the population, PPS: Purchasing power adjusted GDP per capita, and ADGI: Adjusted gross disposable income of households per capita. It was found that for 2010 and 2015 the Netherlands and for 2019 Belgium were ranked as the countries with the highest degree of equality, where Romania and Bulgaria in all three years were ranked as the countries with the lowest degree of equality. For all three years it was found that the RPG and the AGDI indicators are the those with the highest influence on the partial ordering and thus on the mutual ranking.

In the second set of calculation the 6th indicator, AApp: Asylum applications by state of procedure were included. This was done in two different scenarios (a) and (b). Scenario (a): where low numbers were regarded as the more beneficial and scenario (b): where high number were regarded as the more beneficial. Independently of this assumption it was found that the AApp indicator had the overwhelming importance for the overall mutual ranking of the 27 countries. In the first case (a) the Czech Republic was found at the highest rank in both 2015 and 2019, where in second case (b) Luxembourg (2015) and Belgium and the Netherlands (2019) were found at the top.

A special issue, i.e., that in scenario a) Luxembourg and Hungary were found to be isolated countries, i.e., incomparable to any other of the EU member states. This was studied by special partial ordering tools and it was disclosed that the interplay between the PPS, AGDI and the AApp indicators was responsible for this phenomenon.

In addition to the above a set of additional indicators, originally being indicators for other SDGs, were also suggested by Eurostat as important fort the degree of equality. Our partial ordering study indicated that the indicator measuring the share of the population aged 18 to 24 with at most lower secondary education is the most important indicator for ranking the $27 \mathrm{EU}$ member states.

The application of partial ordering methodology to such multi-criteria data systems as, e.g., the SDG 10 seems to be highly advantageous as the calculations not only lead to an overall ranking taking all indicators into account simultaneously without any pretreatment but also to the disclosure of the role of the single indicators that will typically be disguised when a composite indicator is applied in order to achieve a simple linear ranking. Hence, the results of such studies, here exemplified by the SDG10 gives authorities and regulation bodies an advantageous tool to pinpoint and thus select specific areas of focus to reduce the inequalities in their countries. In other words where to spend available funds most beneficially.

Finally it should be noted that Figure 4 (scenario A) has three levels. Having in mind that due to the random procedure of [20] partial orders tend to be asymptotically a threelevel system, the theoretical question appears, whether or not this finding has somewhat to do with the few levels in Figure 4. Usually, another process such as increasing the number of indicators lead to a complete antichain. Therefore, there is some reason to invest some research time on this topic. However, this is outside the scope of the current study.

Further research is clearly motivated by the temporal development. Hence, how will the countries develop over time. With this more or less clear task a further theoretical issue is related. There is still a need of a compact description of how partial orders develop 
as a function of an external parameter, such as time. Finally, the aggregation used by Bruggemann and Carlsen [33] should be examined in more detail as described in [33].

The reader may obviously ask as to how far other partial order methods could be useful. As already mentioned, the study of inequalities is of interest. Then stochastic orders will be of interest too. In that case the point of interest is the quantitative characterization of the data profiles, such as $\left(\mathrm{q}_{1}(\mathrm{x}), \ldots \mathrm{q}_{\mathrm{m}}(\mathrm{x})\right)$. Product order, or orders of majorization theory are not the only tools, partial order can provide. We discussed in former section the role of any single indicator ("sensitivity analysis"), however it could also be of interest to derive a set of logical implications among the indicators. This can be achieved by the powerful tool of the formal concept analysis (FCA) method, developed by mathematicians of the University of Darmstadt [34]. Therein objects have a property or not, i.e., the indicators are binary ( 1 for "has", 0 for "has not"). Therefore, a problem is here that the indicators are multivalued. In the classical FCA the scaling methods are of primary interest in order to transform multivalued indicators into a new set of binary indicators. Recently a method is suggested to avoid the scaling $[35,36]$. As this new developed theory needs still much theoretical work, it is difficult to apply these new concepts.

Author Contributions: Both authors contributed equally to all sections of the paper. Both authors have read and agreed to the published version of the manuscript.

Funding: This research received no external funding.

Institutional Review Board Statement: No studies included studies on human or animals.

Informed Consent Statement: Not applicable.

Data Availability Statement: Data freely available through the references cited.

Conflicts of Interest: The authors declare no conflict of interest.

\section{References}

1. Resolution Adopted by the General Assembly on 25 September 2015. Transforming Our World: The 2030 Agenda for Sustainable Development, General Assembly, Seventieth Session Agenda Items 15 and 116, Oct. 21st, United Nations. 2015. Available online: https://www.un.org/ga/search/view_doc.asp?symbol=A/RES/70/1\&Lang=E (accessed on 31 March 2021).

2. The 17 Goal, United Countrys, Department of Economic and Social Affairs Sustainable Development. 2021. Available online: https:/ / sdgs.un.org/goals (accessed on 31 March 2021).

3. Global Indicator Framework for the Sustainable Development Goalsand Targets of the 2030 Agenda for Sustainable Development, A/RES/71/313E/CN.3/2018/2. 2018. Available online: https://unstats.un.org/sdgs/indicators/Global\%20Indicator\%20 Framework\%20after\%20refinement_Eng.pdf (accessed on 31 March 2021).

4. Measuring Progress towards the Sustainable Development Goals, SDG Tracker. 2018. Available online: https://sdg-tracker.org/ (accessed on 31 March 2021).

5. The Three Pillars of Sustainability, Future Learn. 2021. Available online: https://www.futurelearn.com/info/courses/ sustainability-society-and-you/0/steps/4618 (accessed on 31 March 2021).

6. Reduce Inequality within and among Countries, SDG Tracker. 2018. Available online: https://sdg-tracker.org/inequality\#targets (accessed on 31 March 2021).

7. Sustainable Development in the European Union. Monitoring Report on Progress towards the SDGs in an EU Context, 2020 Edition, Eurostat. 2020. Available online: https:/ / ec.europa.eu/eurostat/documents/3217494/11011074/KS-02-20-202-EN-N. pdf/334a8cfe-636a-bb8a-294a-73a052882f7f?t=1592994779000 (accessed on 31 March 2021).

8. Tosato, M.L.; Marchini, S.; Passerini, L.; Pino, A.; Eriksson, L.; Lindgren, F.; Hellberg, S.; Jonsson, J.; Sjöström, N.; Skagerberg, B.; et al. QSARs based on statistical design and their use for identifying chemicals for further biological testing. Environ. Tox. Chem. 1990, 9, 265-277. [CrossRef]

9. Bock, H.H. Automatische Klassifikation; Vandenhoeck\&Ruprecht: Göttingen, Germany, 1974.

10. Bock, H.H. Clusteranalyse mit unscharfen Partitionen. In Studien zur Klassifikation, Bd 6 Klassifikation und Erkenntnis III-Numerische Klassifikation; Bock, H.H., Ed.; Gesellschaft für Klassifikation: Frankfurt, Germany, 1979; pp. 137-163.

11. Mucha, H.-J.; Bartel, H.-G.; Dolata, J. Techniques of Rearrangements in Binary Trees (Dendrograms) and Applications. Match Commun. Math. Comput. Chem. 2005, 54, 561-582.

12. Marshall, A.W.; Olkin, I. Inequalities: Theory of Majorization and Its Applications; Academic Press: San Diego, CA, USA, 1979.

13. Bruggemann, R.; Patil, G.P. Ranking and Prioritization for Multi-indicator Systems-Introduction to Partial Order Applications; Springer: New York, NY, USA, 2011. 
14. Annoni, P.; Fattore, M.; Bruggemann, R. A Multi-Criteria Fuzzy Approach for Analyzing Poverty structure. Stat. Appl. 2011, 2011, 7-30. [CrossRef]

15. Beycan, T.; Suter, C. Application of Partial Order Theory to Multidimensional Poverty Analysis in Switzerland. In Partial Order Concepts in Applied Sciences; Marco Fattore, R.B., Ed.; Springer: Cham, Switzerland, 2017; pp. 135-150.

16. Fattore, M. Partially Ordered Sets and the Measurement of Multidimensional Ordinal Deprivation. Soc. Indic. Res. 2016, 128, 835-858. [CrossRef]

17. Halfon, E.; Reggiani, M.G. On Ranking Chemicals for Environmental Hazard. Environ. Sci. Technol. 1986, $20,1173-1179$. [CrossRef]

18. Voigt, K.; Welzl, G.; Brüggemann, R. Data analysis of environmental air pollutant monitoring systems in Europe. Environmetrics 2004, 15, 577-596. [CrossRef]

19. Davey, B.A.; Priestley, H.A. Introduction to Lattices and Order; Cambridge University Press: Cambridge, UK, 1990.

20. Prömel, H.J.; Steger, A.; Taraz, A. Phase Transitions in the evolution of Partial Orders. J. Combin. Theory 2001, 94, 230-275. [CrossRef]

21. Bruggemann, R.; Voigt, K. Antichains in partial order, example: Pollution in a German region by Lead, Cadmium, Zinc and Sulfur in the herb layer. MATCH Commun. Math. Comput. Chem. 2012, 67, 731-744.

22. Carlsen, L.; Bruggemann, R.; Kenessova, O.; Erzhigitov, E. Evaluation of analytical performance based on partial order methodology. Talanta 2015, 132, 285-293. [CrossRef] [PubMed]

23. Winkler, P. Average height in a partially ordered set. Discr. Math. 1982, 39, 337-341. [CrossRef]

24. Bubley, R.; Dyer, M. Faster random generation of linear extensions. Discr. Math. 1999, 201, 81-88. [CrossRef]

25. Bruggemann, R.; Sørensen, P.B.; Lerche, D.; Carlsen, L. Estimation of Averaged Ranks by a Local Partial Order Model. J. Chem. Inf. Comp. Sci. 2004, 44, 618-625. [CrossRef] [PubMed]

26. Bruggemann, R.; Carlsen, L. An Improved Estimation of Averaged Ranks of Partially Orders. MATCH Commun. Math. Comput. Chem. 2011, 65, 383-414.

27. De Loof, K.; De Meyer, H.; De Baets, B. Exploiting the Lattice of Ideals Representation of a Poset. Fundam. Inform. 2006, 71, 309-321.

28. De Loof, K.; Rademaker, M.; Bruggemann, R.; De Meyer, H.; Restrepo, G.; De Baets, B. Order Theoretical Tools to Support Risk Assessment of Chemicals. MATCH Commun. Math. Comput. Chem. 2012, 67, 213-230.

29. PyHasse. 2020. Available online: www.pyhasse.org (accessed on 31 March 2021).

30. Carlsen, L. Gender inequality and development. Sustain. Sci. 2020, 15, 759-780. [CrossRef]

31. Bruggemann, R.; Carlsen, L.; Voigt, K.; Wieland, R. PyHasse Software for Partial Order Analysis: Scientific Background and Description of Selected Modules. In Multi-indicator Systems and Modelling in Partial Order; Bruggemann, R., Carlsen, L., Wittmann, J., Eds.; Springer: New York, NY, USA, 2014; pp. 389-423. [CrossRef]

32. Bruggemann, R.; Kerber, A.; Koppatz, P.; Pratz, V. PyHasse, a Software Package for Application Studies of Partial Orderings. In Measuring and Understanding Complex Phenomena; Brüggemann, R., Carlsen, L., Beycan, T., Suter, C., Maggino, F., Eds.; Indicators and Their Analysis in Different Scientific Fields; Springer Nature: Cham, Switzerland, 2021; pp. 291-307. [CrossRef]

33. Bruggemann, R.; Carlsen, L. Uncertainty in weights for composite indicators generated by weighted sums. In Measuring and Understanding Complex Phenomena; Brüggemann, R., Carlsen, L., Beycan, T., Suter, C., Maggino, F., Eds.; Indicators and Their Analysis in Different Scientific Fields; Springer Nature: Cham, Switzerland, 2021; pp. 45-62. [CrossRef]

34. Formal Concept Analysis: Foundations and Applications; Ganter, B.; Stumme, G.; Wille, R. (Eds.) Springer: Berlin, Germany, 2005.

35. Bruggemann, R.; Kerber, A. Evaluations as Sets over Lattices-Application point of view. In Measuring and Understanding Complex Phenomena; Bruggemann, R., Carlsen, L., Beycan, T., Suter, C., Maggino, F., Eds.; Indicators and Their Analysis in Different Scientific Fields; Springer Nature: Cham, Switzerland, 2021; pp. 91-101. [CrossRef]

36. Kerber, A.; Bruggemann, R. Problem Orientable Evaluations as L-subsets. In Measuring and Understanding Complex Phenomena; Bruggemann, R., Carlsen, L., Beycan, T., Suter, C., Maggino, F., Eds.; Indicators and Their Analysis in Different Scientific Fields; Springer Nature: Cham, Switzerland, 2021; pp. 83-89. [CrossRef] 